\title{
NEW ZEALAND SEISMIC HAZARD ANALYSIS
}

\section{T. Matuschka1', K.R. Berryman², A.J. O'Leary³, G.H. McVerry4, W.M. Mulholland ${ }^{5}$ and R.I. Skinner 6}

SUMMARY

The results of a seismic hazard analysis for the country by the Seismic Risk Subcommittee (SRS) of the Standards Association are presented. The SRS was formed in 1979 to advise the Standards Association Loadings Code Amendments Committee on the frequency and level of earthquake ground shaking throughout New Zealand.

Results of the SRS study are in terms of estimates of five percent damped horizontal acceleration response spectra for 50 , 150, 450 and 1000 year return periods. It is intended that these results will form the basis for developing seismic design response spectra for the proposed new Loadings Code (NZS 4203).

\section{INTRODUCTION}

The analysis of seismic hazard in New Zealand by the Seismic Risk Subcommittee (SRS) of the Standards Association of New Zealand was undertaken to assist the Loadings Code Amendments Committee (SANZ) in determining the frequency and level of earthquake shaking throughout New Zealand. The present seismic design loads specified in NZ 4203 : 1976 are similar to those in its predecessor NZ 1900, Chapter 8 (1965) and were based on limited data concerning the rates of earthquake activity in New Zealand and the associated levels of ground shaking. Since that time additional seismological and geological data and strong motion recordings have been gathered. This, along with an expanded research effort, primarily by the DSIR and Universities, has resulted in a significant improvement in our understanding of earthquakes in New Zealand.

Following the NRB Bridge Design Seminar in 1978 considerable effort has been directed at quantifying seismic hazard throughout New Zealand. In 1980 the first attempt at revising and rationalising code seismic design loadings for some years was published by Berrill, Priestley and

Chapman (1) for the New Zealand National Society for Earthquake Engineering (NZNSEE) Bridge Study Group. The elastic acceleration response spectra underlying the seismic coefficients were estimated from the seismic

1 Enaineer, Tonkin \& Taylor Limited, Auckland.

2 New Zealand Geological Survey, DSIR, Lower Hutt.

3 Engineer, Morrison Cooper \& Partners, Wellinaton.

4 scientist, Physics and Engineering Laboratory, DSIR, Lower Hutt.

5 Engineer, Waikato Valley Authority, Hamilton.

6 Scientist, Fhysics and Engineering Laboratory, Lower Hutt. hazard studies of Smith $(2,3)$ (in terms of MM intensity) and Matuschka (4) (primarily in terms of peak ground acceleration). In 1979 with the formation of SRS and the experience of the NZNSEE Bridge Study Group it was apparent that it would be desirable to be able to produce the results of a seismic hazard study directly in terms of acceleration response spectra for code design applications. This prompted studies by Smith and Berryman (5) and McVerry (6) to be undertaken on behalf of the SRS as well as studies by Peek (7), Mulholland (8) and Berrill $(9,10)$ at the University of Canterbury. All these studies have had direct application to the SRS objective and with this research effort our knowledge of seismic hazard in New Zealand has evolved considerably in the past six years.

\section{ANALYSIS OF SEISMIC HAZARD}

Procedures for the evaluation of seismic hazard have been developed into a useful applied seismological and engineering tool over the last 15 years. A probabilistic approach for analysis of seismic hazard was first formulated by Cornell (II), in the late 1960's. The approach has been developed and used to estimate seismic hazard at specific sites in many countries as well as being used to develop contour maps quantifying the variation in seismic hazard throughout regions or countries. Studies of seismic hazard in New Zealand by Matuschka (4), Peek (7), Mulholland (8), and Smith and Berryman (5), have essentially used this approach and a similar approach has been adopted by the SRS.

To assess seismic hazard at any site, information regarding the likely future location of earthquakes, their rate of occurrence, the likely maximum sized earthguake and the intensity of ground shaking which these earthquakes might generate at the site of interest has to be considered. Probabilistic procedures for assessing seismic hazard allow this information to be 
combined in a logical manner to estimate the likely occurrence of events of different intensity levels at a particular site.

The probabilistic approach relies upon two separate models. The first is a seismicity model describing the geographical distribution of earthquakes and the frequency of occurrence of different earthquake magnitudes. The second is an attenuation model describing the probability distribution of intensity of ground shaking produced at a site away from the earthquake source, as a function of earthquake magnitude, source-to-site distance and site subsoil conditions. For specific details of the probabilistic approach readers are referred to references $4,5,7,8$ and 11 .

\section{SEISMICITY MODEL}

Seismicity models of New Zealand have been proposed by Matuschka (4), Peek (7) and Smith and Berryman (5). In these models it is assumed that earthquake occurrence throughout New Zeaiand can be represented by a number of regions in which the seismicity is uniform. The boundaries of the regions were selected from both historical. seismicity and tectonic considerations. Within each region the relative frequency of occurrence of different sized earthquakes is assumed to follow the Gutenburg and Richter recurrence relation

$$
\begin{aligned}
\log \mathrm{N} & =\mathrm{a}-\mathrm{b} \mathrm{M}, \mathrm{M}<\mathrm{M}_{\max } \\
\mathrm{N} & =0, \mathrm{M}>\mathrm{M}_{\max }
\end{aligned}
$$

where $\mathrm{N}$ is the number of earthquakes of magnitude $M$, occurring in any given time, and parameters $a, b$ and $M_{\max }$ vary from region to region. $M_{\max }$ is the maximum magnitude bound.

The Smith and Berryman (5) seismicity model was derived as part of the work of the SRS. This model is shown in Figure 1 and was adopted by the SRS in its seismic hazard study apart for one small modification to Zone $\mathrm{H}$ to reflect latest thinking. Parameters $\mathrm{N}_{4}, \mathrm{~N}_{5}$ and $\mathrm{N}_{6} .5$ are the number of historicaliy observed earthquakes with magnitudes greater than or equal to 4,5 and 6.5 respectively in the time spans stated. The parameter $a_{4}$ gives the annual number of earthquakes with $M 24$ per $1000 \mathrm{~km}^{2}$. In terms of the Gutenburg and Richter parameters $a$ and $b, a_{4}=10(a-4 b)$.

Since its publication in 1983 further geological evidence has been obtained regarding the Alpine Fault region (Zone $\mathrm{H}$ ). Historical seismicity in this region is very low but there is geological evidence (Adams (12), Hull and Berryman (13)) of M 28 earthquakes about once every 500 years, with the last such earthquake of this magnitude occurring several hundred years ago. Consequently, seismicity parameters for Zone $\mathrm{H}$ have been modified as suggested by Berrill (14), to reflect latest thinking. Because the Alpine Fault seems to generate only large earthquakes of magnitude about $7 \frac{1}{2}$ to 8 it was decided to superimpose such a source on a background source accounting for smaller ruptures on lesser faults in the region. Setting the parameters for the background seismicity source according to
1942-1982 levels and those of the large magnitude source to yield a return period of 500 years for $7 \frac{1}{2} \leq M \leq 8$ events, resulted in the following parameters for Zone $\mathrm{H}$ :

$$
\begin{array}{ll}
\text { Zone } \mathrm{H} \text { (i) }: & \mathrm{a}_{4}=0.135, \mathrm{~b}=1.05 \\
& \mathrm{M}_{\max }=7.5 \\
\text { Zone H (ii): } & \mathrm{a}_{4}=0.55, \quad \mathrm{~b}=1.05 \\
& \mathrm{M}_{\min }=7.5, \quad \mathrm{M}_{\max }=8.0
\end{array}
$$

For the purposes of this study a lower limit on earthquake magnitude of 5.25 was adopted. It was considered that structures designed in accordance with current design code standards would not be susceptible to damage from the effects of earthquakes with magnitudes less than 5.25 .

\section{ATTENUATION MODEL}

A number of parameters have been used to quantify the strength of earthquake shaking. The more common include MM intensity, peak ground acceleration and response spectra. For engineering design purposes the most suitable descriptor of design ground motion is a response spectrum, which can be used directly to estimate structural response. The SRS have therefore concentrated efforts on selecting an attenuation model which predicts ground motion response spectra. The attenuation model used by the SRS is based on the model derived from Japanese data by Katayama (15), but modified to fit observed New Zealand data. This model was selected because of similarities between the tectonic environment of Japan and New Zealand, and because studies by Peek (7), and Mulholland (8) at Canterbury University indicated that this model represented recorded New Zealand spectra better than others by Bentley (16) based on a combination of Japanese and US data supplemented by records from other parts of the world and McGuire (17) based on Western US data.

Modifications to the Katayama attenuation model were made by Peek (7) and Mulholland ( 8 ) to correct for the frequency response characteristics of Japanese accelerographs and to reflect the lower standard deviation of spectral accelerations associated with recorded New Zealand strong motion data.

Further modifications were found necessary as a result of the SRS study to reflect the more rapid attenuation of spectral acceleration with distance in New zealand. In Fiordland a magnitude and distance dependent correction factor was introduced to produce lower spectral acceleration estimates than for the rest of the country, in agreement with assigned intensities and measured peak ground accelerations in this area (2). Details of these modifications to the Katayama attenuation model, including a comparison of the Katayama model and recorded New Zealand spectra are summarised by McVerry (6).

The Katayama model enables prediction of ground motion acceleration spectra as a function of earthquake magnitude, epicentral distance and site soil conditions. It assumes isotropic attenuation and although it does not enable direct prediction of 


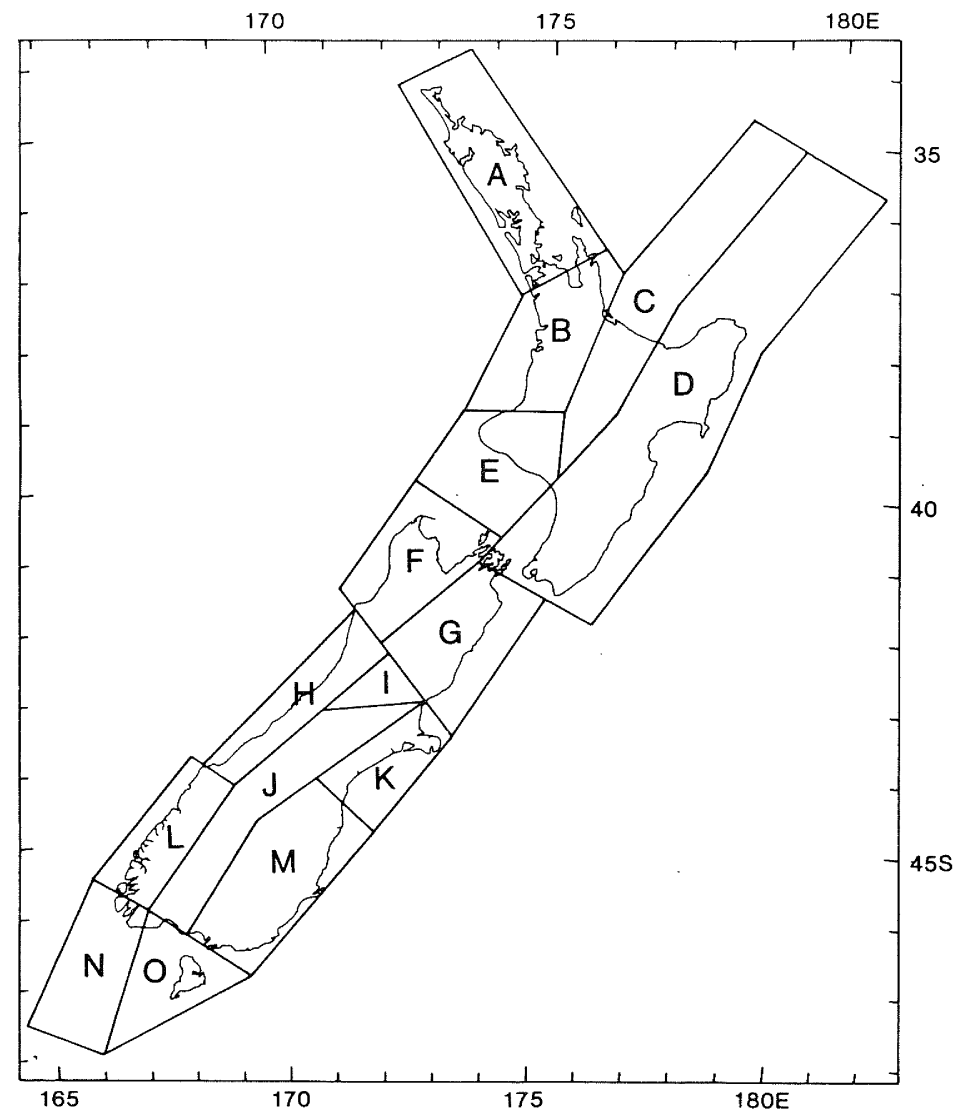

\begin{tabular}{|c|c|c|c|c|c|c|c|c|c|c|}
\hline \multirow[b]{2}{*}{ Region } & \multirow{2}{*}{$\begin{array}{l}\text { area } \\
\mathrm{sq} \mathrm{km}\end{array}$} & \multirow[b]{2}{*}{ b } & \multirow[b]{2}{*}{$M_{\max }$} & \multicolumn{2}{|c|}{$1965-82$} & \multicolumn{2}{|c|}{$1942-82$} & \multicolumn{2}{|c|}{$1840-1982$} & \multirow{2}{*}{$\begin{array}{c}\mathrm{a}_{4} \\
\text { chosen }\end{array}$} \\
\hline & & & & $\mathrm{N}_{4}$ & $a_{4}$ & $\mathrm{~N}_{5}$ & $a_{4}$ & N6.5 & $a_{4}$ & \\
\hline A & 54028 & 1.2 & 7.5 & 3 & 0.003 & 4 & 0.029 & 0 & & 0.03 \\
\hline B & 34288 & 1.2 & 8.0 & 36 & 0.058 & 5 & 0.056 & 0 & & 0.10 \\
\hline c & 23224 & 1.2 & 7.5 & 185 & 0.443 & 21 & 0.350 & 1 & 0.321 & 0.45 \\
\hline D & 89867 & 1.13 & 8.5 & 687 & 0.125 & 159 & 0.582 & 16 & 0.837 & 0.85 \\
\hline E & 31428 & 1.15 & 8.5 & 348 & 0.262 & 22 & 0.241 & 5 & 0.838 & 0.80 \\
\hline $\mathrm{F}$ & 31460 & 1.13 & 8.5 & 280 & 0.495 & 29 & 0.304 & 5 & 0.746 & 0.70 \\
\hline G & 35434 & 1.1 & 8.5 & 154 & 0.242 & 43 & 0.373 & 4 & 0.447 & 0.60 \\
\hline $\mathrm{H}$ & 24366 & 1.05 & 8.5 & 45 & 0.102 & 12 & 0.135 & 0 & & 0.20 \\
\hline I & 6793 & 1.1 & 8.5 & 19 & 0.156 & 7 & 0.317 & 1 & 0.583 & 0.40 \\
\hline $\mathrm{J}$ & 30824 & 1.1 & 8.0 & 41 & 0.074 & 11 & 0.110 & 0 & & 0.11 \\
\hline $\mathrm{k}$ & 19368 & 1.1 & 8.0 & 10 & 0.029 & 2 & 0.032 & 0 & & 0.03 \\
\hline I & 26500 & 0.95 & 8.5 & 316 & 0.662 & 78 & 0.640 & 4. & 0.253 & 0.70 \\
\hline M & 43971 & 1.1 & 8.0 & 16 & 0.020 & 6 & 0.042 & 0 & & 0.08 \\
\hline $\mathrm{N}$ & 31931 & 1.0 & 8.5 & 296 & 0.515 & 40 & 0.306 & 5 & 0.350 & 0.60 \\
\hline 0 & 29304 & 1.1 & 8.0 & 8 & 0.023 & 5 & 0.080 & 0 & & 0.08 \\
\hline
\end{tabular}

Figure 1 The Smith and Berryman Seismicity Model. 
transmission path, focusing or topography effects (which have been documented) these effects are covered implicitly by incorporation of uncertainty associated with the attenuation model in estimates of seismic hazard.

The scatter of strong motion data (peak ground acceleration and response spectral is large and has been found to fit a log normal distribution in many studies (i.e. the logarithms of the observed values are normally distributed about the mean; therefore the observed values are actually skewed about the mean).

The amount of scatter is represented by the standard deviation of the logarithmic residual (residuals are the differences between the observed values and the mean value predicted by an attenuation model for a particular earthquake magnitude and epicentral distance). The Iarger the standard deviation, the larger the scatter of observed data.

The probabilistic seismic hazard approach allows the scattex or uncertainty associated with strong motion data to be incorporated by treating the attenuation model in a probabilistic manner (i.e. for - particular earthquake magnitude and epicentral distance the predicted ground motion is represented by a loc-normal distribution sather than a particular value).

The degree of uncertainty associated With attenuation models and reflected in the assigned standard deviation and its enhancing effect on estimates of seismic hazard are well documented $(6,9,11,18)$. The enhancement effect associated with attenuation uncertainty can be significant and so considerable thought was given to the values adopted in this study. While studies of New Zealand spectral acceleration data $(6,8)$ indicate a lower level of uncertainty than tinat associated with the Katayama attenuation model, it was considered that this might only be because of the relatively small New Zealand data set which is incomplete in recordings of major earthcuakes and moderate earthquakes at short eplcentral distances (i.e. those which are nost damaging). This is addressed by Berril (10) in a recent paper who suggests that in the absence of a sufficiently complete set of New Zealand accelerograms, the New zealand data be combined with the Japanese data of Katayama et al. For estimating scatter or uncertainty parameters. The ustification for this approach is the tectonic and geologic similarity of the two countries. For this study the uncertainty parameters suggested by Berrill (14) and summarised in Table l were adopted.

It is noted that both the Japanese data set upon which the Katayama attenuation model is based and the New Zealand data set, which was used as the basis for modifying the Katayama model, are deficient in strong motion recordings from large magnitude earthquakes at short to moderate epicentral distances (i.e. events which are likely to produce the most severe levels of earthquake shaking). The scarcity of data from such events is unlikely to result in underestimation of spectral accelerations in the

\begin{tabular}{|c|c|}
\hline Natural Period (sec) & $\sigma_{10}$ \\
\hline 0.10 & .275 \\
0.20 & .285 \\
0.30 & .295 \\
0.40 & .30 \\
0.50 & .305 \\
0.70 & .31 \\
21.0 & .32 \\
\hline \multicolumn{2}{|c|}{1.0} \\
deviation of the logarithmic \\
residuals
\end{tabular}

Table 1. Summaxy of $\sigma_{10}$ values adopted for this study

short period end of the spectrum ( $T<0.5 \mathrm{~s}$ ) as moderate sized earthquakes are just as capable of producing high levels of short period spectral acceleration as large events. However, at the long period end of the spectrum ( $T>1.0 \mathrm{~s})$ it is possible that spectral accelerations could be underestimated because it is in this range that large earthquakes could be expected to generate the largest amplitudes. Therefore, attenuation models derived from data sets deficient in large earthquake events at short epicentral distances could possibly under-estimate long period spectral accelerations. Allowance has been made for this possibility by modifying the long period end of the predicted response spectra, as explained later, to ensure that underestimation of long pexiod spectral ordinates does not occur.

\section{RESULTS}

Estimates of five percent damped horizontal acceleration response spectra were calculated for sites on a $0.5 \times 0.5$ degree grid covering the country using the previously discussed seismicity and attenuation models as input into a probabilistic analysis of seismic hazard. Computations were made using the computer programme developed by Mulholland $(8)$. Spectra were calculated for Katayama's ground condition Type III (alluvium of less than 25 metres in depth) as it was considered that this category was most typical of New Zealand sites.

The spectra resulting from the probabilistic seismic hazard analysis represent uniform hazard spectra (i.e. the ordinates of a particular spectrum for different natural periods have an equal probability of being exceeded in a given time interval).

The resulting uniform hazard spectra display a peak at a natural period of $0.2 \mathrm{~s}$ and so spectral accelerations at this period were selected for plotting the variation in seismic hazard throughout New Zealand. The variations in $0.2 \mathrm{~s}$ spectral acceleration throughout New Zealand for average return periods of $50,150,450$ and 1000 years are shown in Figures 2, 3, 4 and 5 respectively. where contours of equal acceleration spectra are plotted.

To investigate the variation in spectral shape throughout the country spectra 

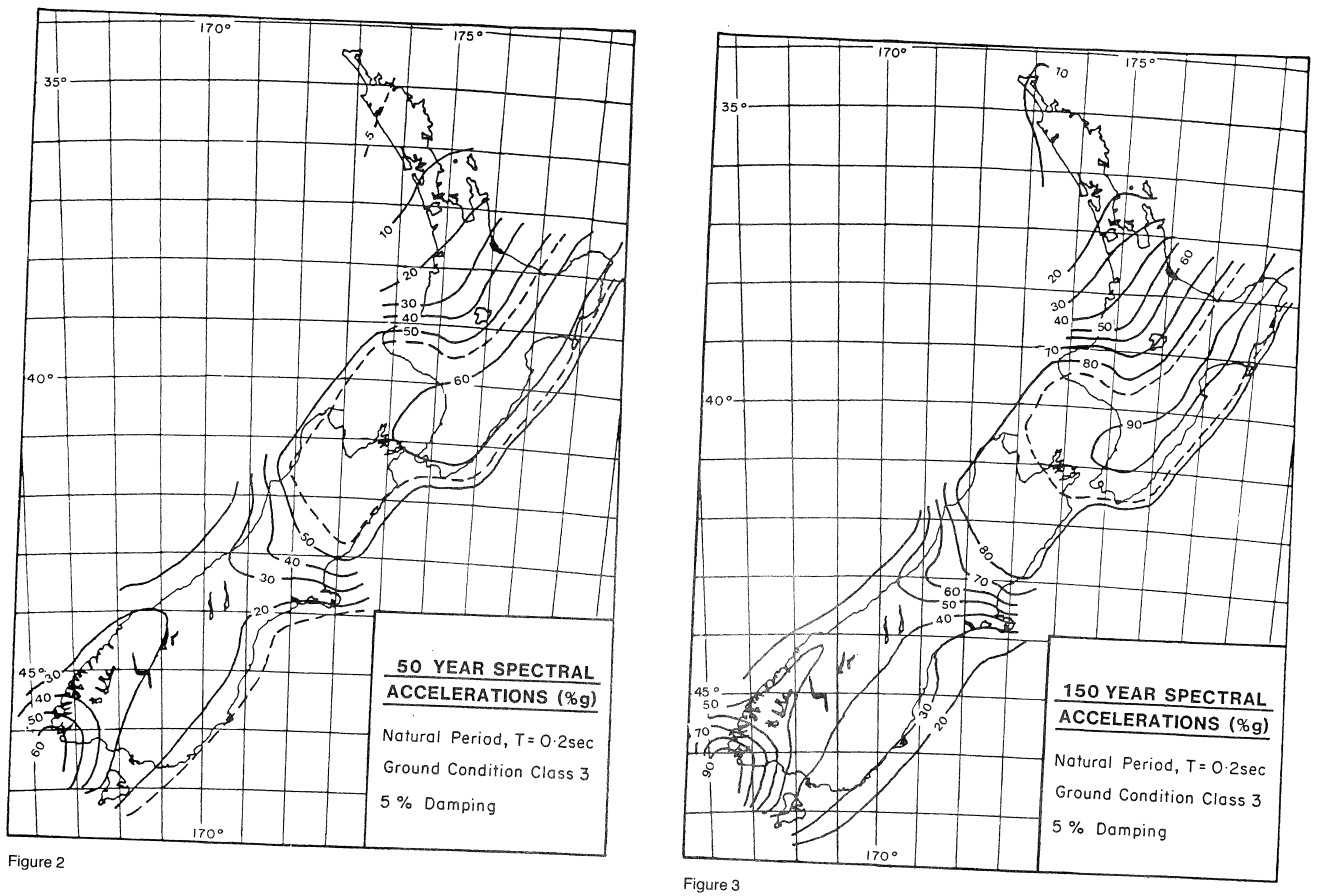

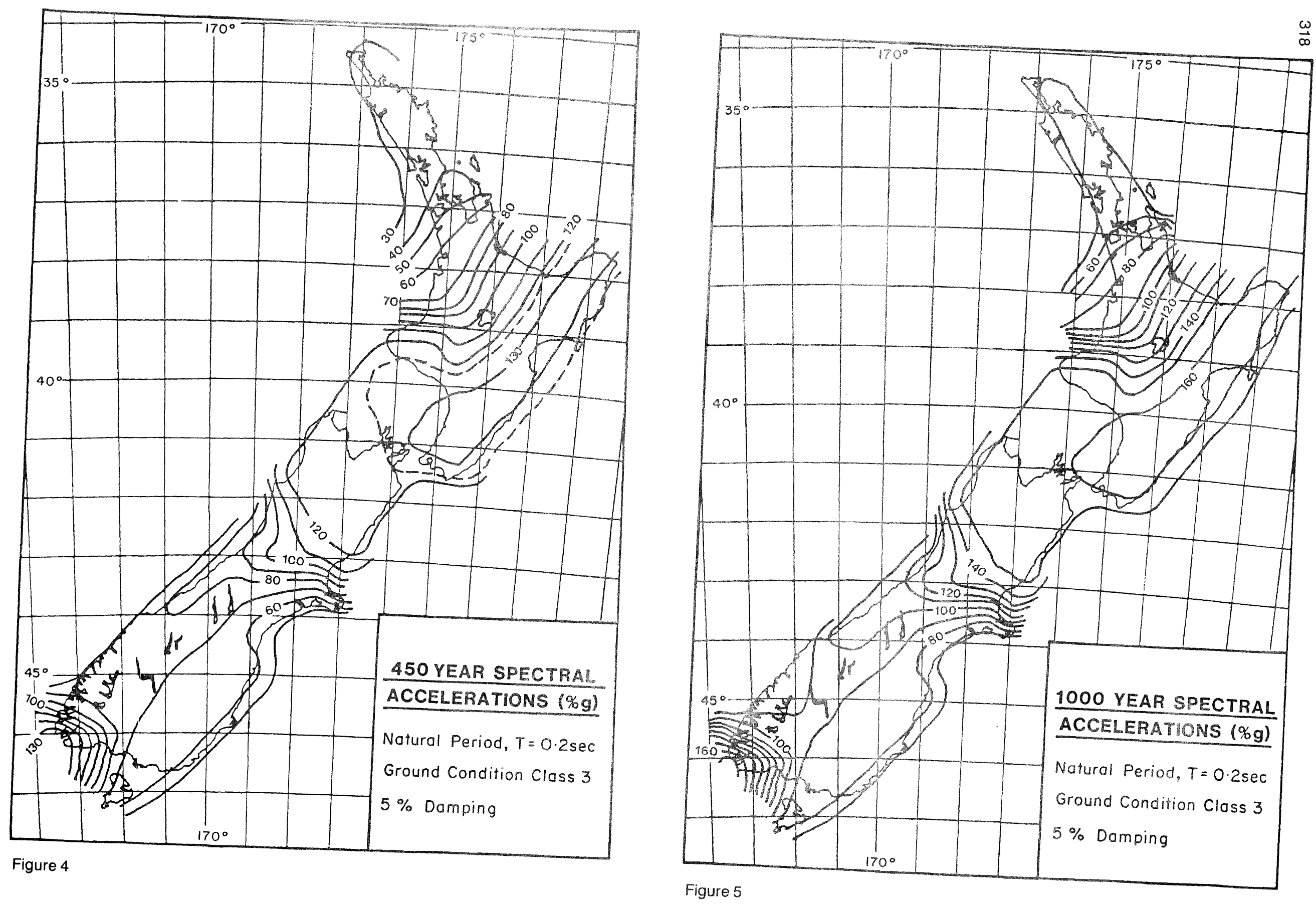
from each site on the $0.5 \times 0.5$ degree grid were normalised to the 0.2 second value and compared. The mean of the normalised spectra for the 450 year average return period and the maximum and minimum normalised spectra are shown in Figure 6. The variation in normalised spectra shape is not significant between sites of low and high seismic hazard. Sites in areas of high seismicity tend to lie above the mean and sites of low seismicity tend to lie below the mean. Similar results were obtained from the 50 150 and 1000 year return period results.

The reason for areas of lower seismicity having higher relative short period ordinates is that in those areas the contribution to seismic hazard, for a particular average return period, comes from smaller magnitude events than in areas of higher seismicity. Smaller magnitude events have response spectra with more pronounced short period peaks (or relatively lower long period ordinates) than larger magnitude events according to the modified Katayama attenuation model and this is supported by observed data.

The fact that spectral shape does not seem to vary significantly is convenient for it suggests that a standard spectrum shape can be adopted for different geographical locations. This would result in some conservatism for lower hazard sites but this is considered acceptable.

To investigate the variations in spectral shape with average return period the mean normalised spectra for the 50, 150, 450 and 1000 year average return periods were compared and found to be almost identical except for a slight relative increase in the long period end of the normalised spectra with increasing average return period. This result reflects the greater contribution to seismic hazard from larger magnitude events for increasing average return period. Large magnitude events produce relatively higher long period spectral ordinates. However, the variation in spectral shape with average return period is not significant, a convenient result for it allows the adoption of a standard spectrum shape for different average return periods.

The shapes of the normalised spectra are most close to those predicted by the modified Katayama attenuation model for earthquakes occurring at short epicentral distances (i.e. less than $60 \mathrm{~km}$ ). Analysis of the results indicates that even for areas of low seismicity the major contribution to seismic hazard comes from local earthquakes rather than from distant large events.

Comparison of the normalised spectra shown in Figure 6 with typical spectra indicate that they lie within the range of shapes of typical single earthquakes occurring at relatively short epicentral distances. The peak occurs at a natural period of 0.2 seconds which, by comparison with the modified Katayama attenuation model, is most consistent with moderate magnitude $(5.25 \leq M<7)$ events occurring at relatively short epicentral distances. Large magnitude events $(M \geq 7.0)$ tend to produce spectra which peak at slightly longer periods than moderate magnitude events. For example, the modified Katayama model indicates a spectral peak at a period of 0.3 seconds for earthquakes with $6.8 \leq M<7.5$ and $20 \leq R<60 \mathrm{~km}$ where $R$ is epicentral distance. It is noted that as the epicentral distance increases the spectral peak occurs at longer periods (because of the more rapid attenuation of the higher frequency waves) and this is reflected in the modified Katayama attenuation model which indicates a spectral peak at a period of 0.5 seconds for earthquakes with $6.8 \leq M<7.5$ and $120 \leq R<200 \mathrm{~km}$. The results of the seismic hazard analysis in terms of spectral acceleration and the above observation indicate that it is the more frequent moderate magnitude events which contribute most significantly to seismic hazard at most sites in New zealand rather than the less frequent large events.

It is recommended that a smoothed version of the 450 year upper bound spectrum shown plotted in Figure 6 but modified to have constant velocity spectral ordinates for periods greater than 1.0 second be used as the basis for developing design response spectra for Type III ground conditions. The recommended nomalised spectrum in shown on Figure 7 along with the smoothed 450 year upoer bound spectrum. The assumption of a constant velocity spectrum for periods greater than $1.0^{\circ}$ second is justified on the following grounds:

(i) to account for possible underestimation of long period spectral ordinates in the attenuation model used in this study (because of a scarcity of strong motion recordings of large earthquakes at short epicentral distances).

(ii) to provide greater weighting to large magnitude events (which have relatively higher long period ordinates) which because of their longer duration of shaking than moderate magnitude events have a greater damage potential which is not reflected in a response spectrum.

The assumption of a constant velocity spectrum between spectral periods of 0.5 to about 5 seconds has previously been suggested by Newmark and Hall (19).

\section{SUMMARY}

(1) The results of the seismic hazard study by the Seismic Risk Committee presented in this paper are based on carefully conceived models of seismicity and spectral acceleration attenuation which have been developed as part of the study and are considered appropriate for New Zealand. The results are in terms of uniform hazard horizontal ground acceleration response spectra and are appropriate for site soil conditions consisting of alluvium less than 25 metres in depth (i.e. Katayama's ground condition Type III). It was considered that ground condition Type III was most typical of New Zealand sites. Comparison of the uniform hazard spectra with typical spectra indicate that they lie within the range of shapes of typical single moderate magnitude earthquakes occurring at relatively short epicentral distances. 


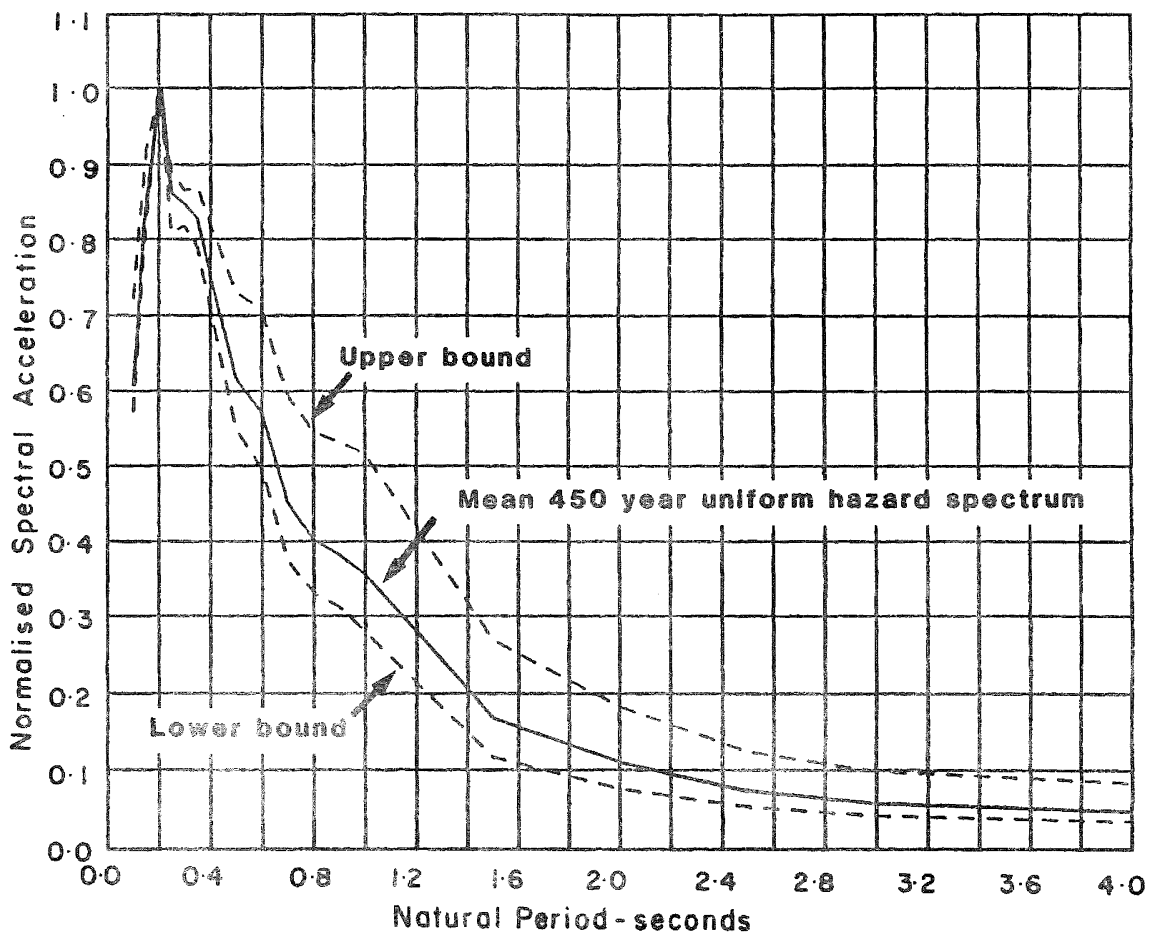

Figure 6 Normalised 450 year uniform hazard spectra.

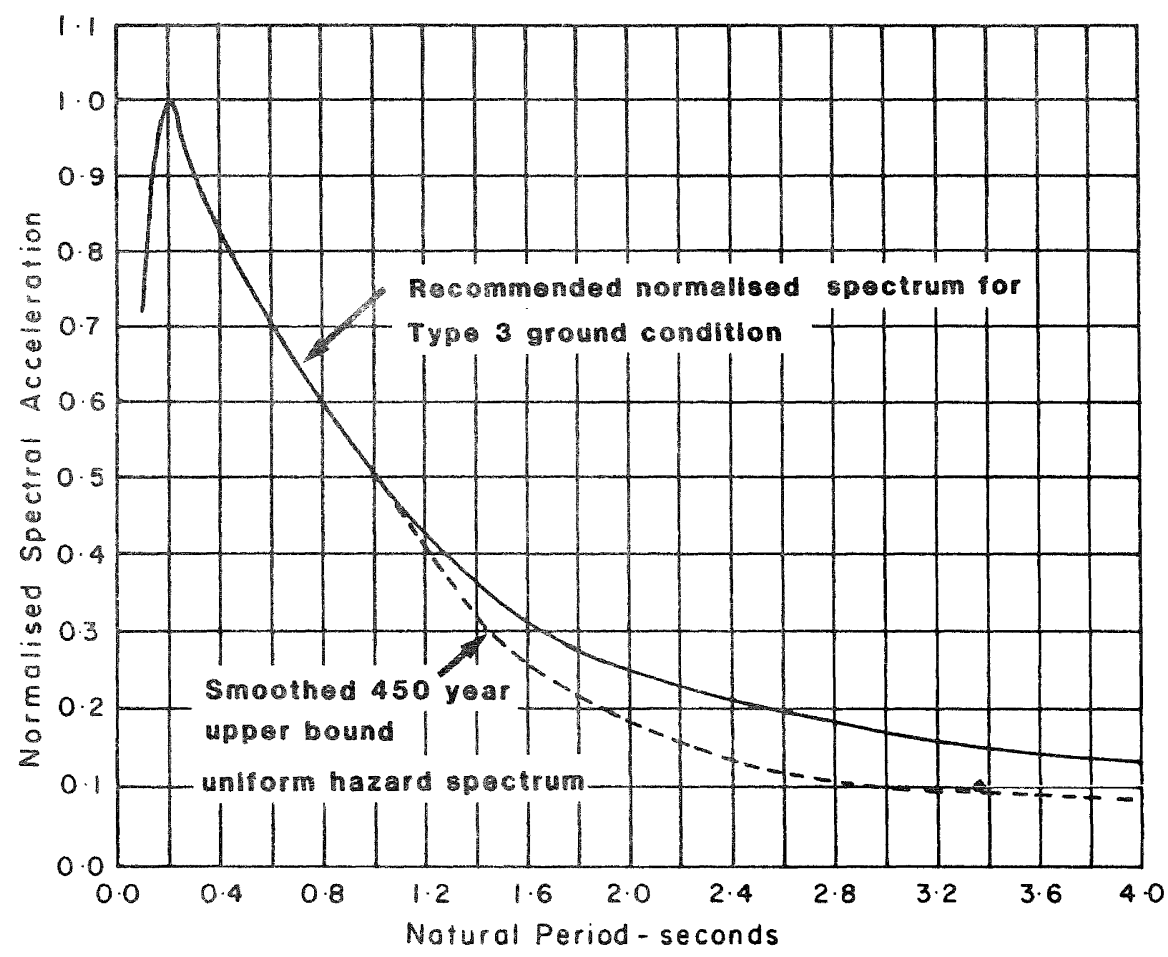

Figure 7 Normalised spectrum for type 3 ground conditions recommendeut as basis for developing code design spectra. 
(2) It is intended that the results will form the basis for developing design response spectra for the Loadings Code NZS 4203. The normalised spectrum recommended as the basis for developing design spectra (Figure 7) is based on the results of a probabilistic seismic hazard analysis but modified at the long period end to have constant velocity spectral ordinates for periods greater than 1.0 second. This modification was made because of the possible under-estimation of long period spectral acceleration by the attenuation model used in this study (a consequence of the scarcity of strong motion data from large earthquakes recorded at short epicentral distances) and to effectively provide greater weighting to large magnitude events, which because of their longer duration of shaking than moderate magnitude events have a greater damage potential which is not reflected in a response spectrum.

The recommended normalised spectrum shown on Figure 7 should not be construed as a code design spectrum as modifications may be made to both short and long period ordinates to ensure that values are appropriate for modal analysis or equivalent lateral force design procedures.

(3) Work is currently being undertaken to establish normalised spectra appropriate for other soil conditions and to consider the potential for allowing for the effect of soil-structure interaction in reducing short period spectral ordinates. It is intended to define two other site soil conditions. one for hard rock sites and the other for soft soil sites. It is also intended to provide guidelines for identifying soft soils which could yield when subjected to earthquake shaking or potentially liquefiable soils for which specialised site specific studies may be warranted.

(4) Modifications to the seismic hazard results can be expected in the future as our understanding of earthquakes in New Zealand increases. The results produced in this study assume that earthquakes occur randomly in time (i.e. they follow a Poisson process). With an increased knowledge of the tectonics of different regions a non-Poissonian assumption could be adopted. For example, recent studies of the Alpine Fault $(12,13)$ suggest that large (magnitude $7 \frac{1}{2}$ to 8 ) events have occurred regularly at approximately 500 year intervals over the central section of this fault. The last fault movement occurred at least several hundred years ago and so there is a relatively high probability that a large earthquake event associated with the central Alpine Fault will cause high levels of ground shaking at the site in the next 100 years or so. Consequently, it could be argued that the level of seismic hazard in this area should be increased above that indicated from the results presented in this study. Such second generation hazard studies are beyond the scope of this general, New Zealand-wide review.

\section{ACKNOWLEDGEMENTS}

The authors wish to acknowledge the assistance of Dr J.B. Berrill and Dr W.D. Smith, who have contributed significantly to this study both when they were members of the Seismic Risk Subcommittee and subsequently when work commitments prevented them from being fully involved in the Subcommittee's work. In addition, the support, assistance and review comments by Mr A.L. Andrews and Dr D.L. Hutchison who have been involved with liasing with the Subcommittee and who will be responsible for incorporating the results into the new Loadings Code, NZS 4203, have been greatly appreciated.

\section{REFERENCES}

(1) Berrill, J.B., Priestley, M.J.N. and Chapman, H.E. (1980) "Design Earthquake Loading and Ductility Demand", Bulletin NZNSEE, Vol. 13, No. 3 , pp. 232-241.

(2) Smith, W.D. (1978a) "Spatial Distribution of Felt Intensities for New Zealand Earthquakes", New Zealand Journal of Geology and Geophysics 21 : pp. 293-311.

(3) Smith, W.D. (1978b) "Earthquake Risk in New Zealand: Statistical Estimates" New Zealand Journal of Geology and Geophysics.

(4) Matuschka, T. (1980) "Assessment of Seismic Hazard in New Zealand", University of Auckland, Department of Civil Engineering, Report No. 222.

(5) Smith, W.D. and Berryman, K. (1983) "Revised Estimates of Earthquake Hazard in New Zealand", Bulletin NZNSEE, Vol. 16, No. 4', pp. 259-272.

(6) McVerry, G.H. (1985) "Uncertainties in Attenuation Relations for New Zealand Seismic Hazard Analysis". Paper presented at the Annual Conference of the Institute of Professional Engineers, Wellington, New Zealand, and submitted to Bulletin NZNSEE.

(7) Peek, R. (1980) "Estimation of Seismic Risk for New Zealand", Department of Civil Engineering Research Report $(80-21)$, University of Canterbury.

(8) Mulholland, W.M. (1982) "Estimation of Design Earthquake Motion for New Zealand", Department of Civil Engineering Research Report (82-9), University of Canterbury.

(9) Berrill, J.B. (1985) "Seismic Hazara Analysis and Design Loads" Bulletin NZNSEE, Vol. 18, No. 2, pp. 139-150.

(10) Berrill, J.B. (1985) "Distribution of Scatter in New Zealand Accelerograph Data", Bulletin NZNSEE, Vol. 18 , No. 2 , pp. 151-164.

(11) Cornel1, C.A. (1968) "Engineering Seismic Risk Analysis", Bulletin Seismological Society of America, 58 (5) , pp. 1583-1606.

(12) Adams, J. (1980) "Paleoseismicity of the Alpine Fault Seismic Gap, New 
Zealand", Geology, 8, 00. 72-76.

(13) Hull, A.G. and Berryman, K.R. (in press) "Holocene Tectonism in the Region of the Alpine Fault, Lake McKerrow, Fiordland", Proceedings of Recent Crustal Movements Symposium, Royal Society of New Zealand Bulletin.

(14) Berrill, J.B. (1985), personal communication.

(15) Katayama, T. (1982) "An Engineering Prediction Model of Acceleration Response Spectra and its Application to Seismic Hazard Mapping", Earthquake Engineering and Structural Design, 10, pp. 149-163.

(16) Bentley, R.J. (1979) "Average Estimates of the Attenuation with Distance of $5 \%$ Damped Horizontal Acceleration Response Spectra" , Proc. Second South Pacific Regional Conference on Earthquake Engineering, Wellington.

(17) McGuire, R.K. (1974) "Seismic Structural Response Risk Analysis, Incorporating Peak Responses Regressions on Earthquake Magnitude and Distance", Department of Civil Engineering Research Report R74-51, Massachusetts Institute of Technology, Cambridge, Massachusetts.

(18) Bender, B. (1984) "Incorporating Acceleration Variability into Seismic Hazard Analysis", Bulletin Seismological Society of America, 74, pp 14511462 .

(19) Newmark, N.M. and Hall, W.J. (1982) "Earthquake Spectra and Design", Earthquake Engineering Research Institute Monograph. 